\title{
Exposure to air pollutants in hospitals: indoor-outdoor correlations
}

\author{
A. Chamseddine \& M. El-Fadel \\ Department of Civil and Environmental Engineering, \\ American University of Beirut, Lebanon
}

\begin{abstract}
This study presents an assessment of exposure to air pollutants in a hospital environment using several air quality indicators commonly associated with indoor and outdoor emission sources including carbon monoxide (CO), carbon dioxide $\left(\mathrm{CO}_{2}\right)$, fine particulate matter $\left(\mathrm{PM}_{2.5}\right)$, and total volatile organic compounds (TVOC). The distribution and variation of indoor concentrations of $\mathrm{CO}, \mathrm{CO}_{2}, \mathrm{PM}_{2.5}$ and TVOC were examined in ten working areas of three hospitals randomly selected in an urban and rural setting. Indoor concentrations were then statistically correlated with outdoor sources. The results showed higher levels of $\mathrm{CO}_{2}(690 \pm 65 \mathrm{ppm})$ and TVOC $(0.30 \pm 0.10 \mathrm{ppm})$ indoors $(p<$ $0.05)$ compared to outdoors $(471 \pm 85 \mathrm{ppm}$ and $0.10 \pm 0.07 \mathrm{ppm}$, respectively). A high correlation $(r=0.69)$ was recorded between indoor and outdoor $\mathrm{PM}_{2.5}$ levels suggesting that indoor environments are directly affected by outdoor levels. At most sampling sites, outdoor $\mathrm{PM}_{2.5}$ and $\mathrm{CO}$ concentrations $(p<0.05)$ were higher than indoor levels. While the $\mathrm{PM}_{2.5}$ indoor/outdoor $(\mathrm{I} / \mathrm{O})$ ratio was less than 1 indicating a cleaner indoor environment and minimal indoor $\mathrm{PM}_{2.5}$ sources, indoor levels exceeded outdoor concentrations during a dust storm and reached a 2.6 fold higher than the WHO standard. Higher $\mathrm{PM}_{2.5}$ and $\mathrm{CO}$ levels were recorded in urban hospitals $\left(\mathrm{PM}_{2.5}=81 \pm 12 \mu \mathrm{g} / \mathrm{m}^{3}\right.$ and $\mathrm{CO}=$ $4.62 \pm 0.71 \mathrm{ppm})$ compared to rural $\left(\mathrm{PM}_{2.5}=27 \pm 6.5 \mu \mathrm{g} / \mathrm{m}^{3}\right.$ and $\mathrm{CO}=1.22 \pm$ $0.43 \mathrm{ppm})$ suggesting the contribution of construction activities and vehicular emissions to urban levels of $\mathrm{PM}_{2.5}$ and $\mathrm{CO}$ in hospitals. Although affected by outdoor levels, most indoor $\mathrm{PM}_{2.5}$ and $\mathrm{CO}$ concentrations in both urban and rural setting remained below standards.

Keywords: hospital environment, indoor air quality, $\mathrm{CO}, \mathrm{CO}_{2}, \mathrm{PM}_{2.5}$, TVOC.
\end{abstract}




\section{Introduction}

Most air pollutants are encountered in the troposphere as a result of photochemical reactions, biomass burning, vehicle and industrial emissions that could be of natural or anthropogenic sources [1]. These pollutants are classified as primary (emitted directly into the atmosphere including mineral dust, and gaseous precursors such as $\mathrm{SO}_{2}, \mathrm{NO}_{\mathrm{x}}$ and $\mathrm{NH}_{3}$ ) or secondary pollutants (formed through chemical reactions). Other pollutants featuring $\mathrm{CO}$, elemental and organic carbon result from automotive, industrial sources and incomplete combustion [2]. Once in the atmosphere, pollutants are subject to dispersion, condensation, coagulation, physicochemical transformations, thus forming secondary pollutants $[1,2]$. In addition to their significant impacts on regional and global climate change, pollutants are associated with adverse health and environmental impacts [3-5]. Since people spend most of their times indoors the effect of indoor air quality (IAQ) on health is invariably more pronounced than outdoor air with IAQ in certain sensitive environments such as hospitals being more critical to its occupants negating the purpose of the visit if IAQ deteriorates $[5,6]$. Several studies have explored the relation between hospital admissions and atmospheric concentration of fine particulate matter and trace gaseous species [7, 8], and have examined the impacts of haze on hospital admissions [9, 10]. On a normal day in Lebanon, between 40 and 60 patients are received at the outpatient department (OPD) of urban hospitals, 30\% (between 12 and 18) of which are admitted to the appropriate specialty at the inpatient department (IPD) depending on the presenting symptoms. It is also noteworthy that hospital OPD and IPD admissions increase by about $20 \%$ during dust storm events where high levels of fine particulate matter and gaseous species are experienced $[9,10]$. Hospitals act as specific indoor environments with highly vulnerable individuals potentially exposed to various air pollutants exacerbating health risks [11]. Therefore, this study targets the assessment of IAQ determinants in hospitals located in congested urban areas and pristine rural areas with emphasis on indoor-outdoor correlations and associated potential exposure.

\section{Materials and methods}

\subsection{Hospital selection}

Three hospitals (referred to as hospital A, B and C in the rest of this paper) in Lebanon were randomly selected from urban and rural areas, and 2 to 6 sampling sites within each hospital were chosen for IAQ monitoring during the months of March and April 2013, and November 2014. A total of ten working areas of the three hospitals were sampled and included clinics, clinic waiting areas, lobbies, reception, staff offices, corridors, pediatrics patient rooms, emergency rooms (ER), basement workshops, and meeting rooms. One to two outdoor site of each hospital were selected to represent fresh air intake. 


\subsection{Air quality monitoring}

Indoor and outdoor levels of carbon monoxide $(\mathrm{CO})$, carbon dioxide $\left(\mathrm{CO}_{2}\right)$, fine particulate matter $\left(\mathrm{PM}_{2.5}\right)$, and total volatile organic compounds (TVOC) were monitored during working hours (9:00 am-5:00 pm) at the hospitals. A Langan L76n air quality analyser was used to measure real time $\mathrm{CO}$ and $\mathrm{CO}_{2}$ concentrations (ppm), temperature $\left({ }^{\circ} \mathrm{C}\right)$ and relative humidity (\%). Two DustTrak $^{\mathrm{TM}}$ II Aerosol Monitor (Model 8532, TSI Corporation, Shoreview, USA) equipped with a light-scattering laser photometer to measure real-time concentrations was used for monitoring outdoor and indoor $\mathrm{PM}_{2.5}$ concentrations simultaneously. A real-time PhoCheck Tiger PID instrument (Ion Science Ltd, The Way, Fowlmere, UK) was used to monitor TVOC levels (ppm).

\subsection{Statistical analysis}

The concentration variation of air pollutants were analysed by one-way analysis of variance (one-way ANOVA) for different sampling sites. Pearson productmoment correlation coefficient (PCC) $(r)$ was also used as a measure of linear correlation to analyse the relation between indoor levels and outdoor pollutants. Statistical significance was set at $p<0.05$.

\section{Results and discussion}

\subsection{IAQ in different working areas}

Recorded levels of $\mathrm{CO}, \mathrm{CO}_{2}, \mathrm{PM}_{2.5}$ and TVOC were significantly different $(p<0.05)$ in different working areas. The average concentrations of indoor CO were $3.24 \pm 0.23,1.08 \pm 0.06,1.58 \pm 0.04,2.62 \pm 0.19,1.55 \pm 0.05,1.39 \pm 0.07$, $1.65 \pm 0.04,1.90 \pm 0.28,2.13 \pm 0.10$, and $1.82 \pm 0.14 \mathrm{ppm}$ in the clinic, clinic waiting area, lobby, reception, staff office, corridor, pediatrics patient room, emergency room (ER), basement workshop, and meeting room respectively (Table 1). At all sampling sites average indoor levels of $\mathrm{CO}(p<0.05)$ were lower than the NAQQS standards (i.e. 9 ppm for 8 hours and 35 ppm for 1 hour). At most sampling sites, outdoor CO concentrations $(p<0.05)$ were higher than indoor levels (Table 2) and also below standards indicating that although urban hospitals are exposed to $\mathrm{CO}$ sources such as vehicular emissions, both indoor and outdoor levels remained within acceptable limits. Furthermore, at higher elevation $\left(5^{\text {th }}\right.$ and $8^{\text {th }}$ floor $) \mathrm{CO}$ exposure becomes minimal [12].

Indoor $\mathrm{CO}_{2}$ concentrations were higher than outdoor levels (Tables 1 and 2) due to human metabolism and breathing in indoor closed environments but remained below the $1000 \mathrm{ppm}$ limit ranging from $371 \pm 19.7 \mathrm{ppm}$ to $690 \pm 65.2$ ppm (Table 1). When $\mathrm{CO}_{2}$ levels exceed $1000 \mathrm{ppm}$ in indoor environments, it is advisable to enhance air exchange / ventilation rates $[12,13]$.

Indoor $\mathrm{PM}_{2.5}$ concentrations were significantly different among sampling sites $(p<0.05)$. Critical indoor environments such as pediatrics patient room $(12.8 \pm$ $\left.1.01 \mu \mathrm{g} / \mathrm{m}^{3}\right)$ and emergency room $\left(24.0 \pm 4.18 \mu \mathrm{g} / \mathrm{m}^{3}\right)$ exhibited relatively low levels within the WHO standard $\left(25 \mu \mathrm{g} / \mathrm{m}^{3}\right)$. However, at clinic, reception and 
Table 1: Concentrations of indoor pollutants at sampled working areas.

\begin{tabular}{|c|c|c|c|c|c|}
\hline \multirow[b]{2}{*}{ ID } & \multirow[b]{2}{*}{ Working area } & \multicolumn{4}{|c|}{ Mean \pm Std. } \\
\hline & & $\mathrm{CO}(\mathrm{ppm})$ & $\mathrm{CO}_{2}(\mathrm{ppm})$ & $\mathrm{PM}_{2.5}\left(\mu \mathrm{g} / \mathrm{m}^{3}\right)$ & TVOC (ppm) \\
\hline 1 & Clinic & $3.24 \pm 0.23$ & $690 \pm 65.2$ & $90.1 \pm 13.6^{\mathrm{a}}$ & $\mathrm{NR}^{\mathrm{b}}$ \\
\hline 2 & Clinic waiting area & $1.05 \pm 0.06$ & $571 \pm 38.1$ & $22.9 \pm 1.90$ & $0.08 \pm 0.07$ \\
\hline 3 & Lobby & $1.58 \pm 0.04$ & $447 \pm 8.47$ & $23.7 \pm 4.70$ & NR \\
\hline 4 & Reception & $2.62 \pm 0.19$ & $604 \pm 29.8$ & $80.8 \pm 15.7^{\mathrm{a}}$ & NR \\
\hline 5 & Staff office & $1.55 \pm 0.05$ & $526 \pm 21.4$ & $9.93 \pm 1.86$ & NR \\
\hline 6 & Corridor & $1.39 \pm 0.07$ & $406 \pm 19.9$ & $15.2 \pm 1.04$ & $0.30 \pm 0.10$ \\
\hline 7 & Pediatrics room & $1.65 \pm 0.04$ & $497 \pm 17.6$ & $12.8 \pm 1.01$ & NR \\
\hline 8 & Emergency room (ER) & $1.90 \pm 0.28$ & $371 \pm 19.7$ & $24.0 \pm 4.18$ & NR \\
\hline 9 & Basement workshop & $2.13 \pm 0.10$ & $483 \pm 10.8$ & $11.8 \pm 1.30$ & NR \\
\hline 10 & Meeting room & $1.82 \pm 0.14$ & $550 \pm 12.5$ & $34.1 \pm 1.15$ & $0.15 \pm 0.11$ \\
\hline & $p-$ Value $^{\mathrm{c}}$ & $<0.05$ & $<0.05$ & $<0.05$ & $<0.05$ \\
\hline
\end{tabular}

${ }^{a}$ High levels were reported during sampling in April 2013 due to a Dust storm event. ${ }^{b}$ No TVOC levels were recorded. ${ }^{\circ}$ One way ANOVA $(95 \% \mathrm{CI})$ for different working areas (statistical significance was set at $p<0.05$ ).

Table 2: Concentrations of outdoor pollutants at fresh air intake sites.

\begin{tabular}{llcccc}
\hline & & \multicolumn{4}{c}{ Mean \pm Std. } \\
\cline { 3 - 6 } ID & Working area $^{\text {a }}$ & $\mathrm{CO}(\mathrm{ppm})$ & $\mathrm{CO}_{2}(\mathrm{ppm})$ & $\mathrm{PM}_{2.5}\left(\mu \mathrm{g} / \mathrm{m}^{3}\right)$ & $\mathrm{TVOC}(\mathrm{ppm})$ \\
\hline 1 & $1^{\text {st }}$ floor entrance & $4.62 \pm 1.25$ & $471 \pm 84.7$ & $81.1 \pm 12.2^{\mathrm{b}}$ & $\mathrm{NR}^{\mathrm{c}}$ \\
2 & $8^{\text {th }}$ Mechanical & $1.08 \pm 0.16$ & $387 \pm 8.36$ & $71.7 \pm 6.63$ & $0.05 \pm 0.02$ \\
3 & $1^{\text {th }}$ Mechanical & $1.93 \pm 0.06$ & $397 \pm 7.53$ & $20.5 \pm 1.03$ & $\mathrm{NR}$ \\
4 & $1^{\text {st }}$ floor entrance & $3.31 \pm 0.74$ & $377 \pm 22.4$ & $77.5 \pm 12.8^{\mathrm{b}}$ & $\mathrm{NR}$ \\
5 & $8^{\text {th }}$ Mechanical & $2.39 \pm 0.12$ & $443 \pm 7.66$ & $46.8 \pm 6.57$ & $\mathrm{NR}$ \\
6 & $8^{\text {th }}$ Mechanical & $1.02 \pm 0.12$ & $438 \pm 7.21$ & $75.3 \pm 8.78$ & $0.10 \pm 0.07$ \\
7 & $11^{\text {th }}$ Mechanical & $2.35 \pm 0.44$ & $418 \pm 47.8$ & $68.4 \pm 6.86$ & $\mathrm{NR}$ \\
8 & ER main entrance $^{\text {th }}$ & $1.22 \pm 0.43$ & $288 \pm 4.66$ & $26.7 \pm 6.46$ & $\mathrm{NR}$ \\
9 & $8^{\text {th }}$ Mechanical & $1.28 \pm 0.05$ & $341 \pm 8.15$ & $46.5 \pm 4.18$ & $\mathrm{NR}$ \\
10 & $11^{\text {th }}$ Mechanical & $1.08 \pm 0.13$ & $505 \pm 13.4$ & $39.8 \pm 1.49$ & $0.05 \pm 0.01$ \\
\hline & $p-$ Value $^{\mathrm{d}}$ & $<0.05$ & $<0.05$ & $<0.05$ & $<0.05$ \\
\hline
\end{tabular}

${ }^{a}$ Outdoor sampling sites were conducted simultaneously with indoor measurements and were chosen to represent fresh air intake into the indoor working areas. ${ }^{b}$ High levels were reported during sampling in April 2013 due to a Dust storm event. ${ }^{\mathrm{C} N o}$ TVOC levels were recorded. ${ }^{\mathrm{d}}$ One way ANOVA $(95 \% \mathrm{CI})$ for different working areas (statistical significance was set at $p<0.05$ ).

meeting rooms, levels exceeded the WHO standard by reaching $90.1 \pm 13.6$, $80.8 \pm 15.7$, and $34.1 \pm 1.15 \mu \mathrm{g} / \mathrm{m}^{3}$, respectively (Table 1 ). These levels may be attributed to human activities in meeting rooms and a dust storm event that took place during sampling at the clinic and reception at an urban hospital (B). Figure 1 shows the backward air trajectory of the sampling day that was conducted at the clinic and reception, revealing a dust storm from the Arabian Desert in Saudi Arabia. High levels of $\mathrm{PM}_{2.5}$ are carried with dust storms and can affect indoor $\mathrm{PM}_{2.5}$ levels [14]. The outdoor $\mathrm{PM}_{2.5}$ concentrations during the dust event $(p<0.05)$ have also exceeded the WHO standard reaching $81.1 \pm 12.2$ and $77.5 \pm 12.8 \mu \mathrm{g} / \mathrm{m}^{3}$ at the outdoor site ( $1^{\text {st }}$ floor entrance) of the clinic and 
reception working areas, respectively (Table 2). The high levels of outdoor $\mathrm{PM}_{2.5}$ may be attributed to the proximity of the sampling sites to on-road vehicular emissions and to dusty weather experienced during sampling.

In a similar behavior to $\mathrm{CO}_{2}$, higher TVOC levels $(0.30 \pm 0.10 \mathrm{ppm})$ were recorded indoors $(p<0.05)$ than outdoors $(0.10 \pm 0.07 \mathrm{ppm})$. TVOCs were recorded in clinic waiting area, corridor and meeting room which are exposed to frequent floor-cleaning and air refreshers that are sources of TVOC [12].

NOAA HYSPLIT MODEL

Backward trajectory ending at 0000 UTC 01 Apr 13

GDAS Meteorological Data

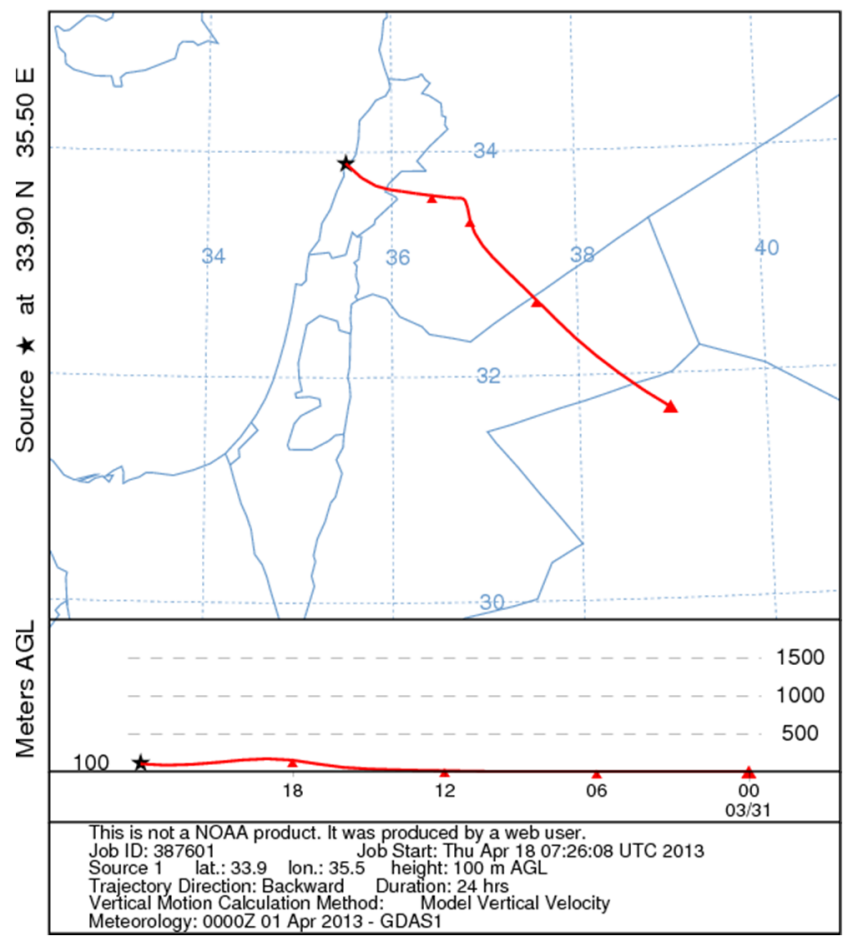

Figure 1: HYSPLIT model with backward air trajectory of dust storm originating from the Arabian Desert in Saudi Arabia during sampling at clinic and reception working areas of Hospital B.

\subsection{Indoor-outdoor correlations}

Table 3 presents the average indoor and outdoor concentration ratios for $\mathrm{CO}$, $\mathrm{CO}_{2}, \mathrm{PM}_{2.5}$ and TVOC in various working areas. Few areas exhibited $\mathrm{CO}$ ratios $>1$ (corridor: 1.36, ER 1.56, basement workshop: 1.66, meeting room: 1.69). Combustion is a major contributor of $\mathrm{CO}$ in indoor environments $[15,16]$ and 
few combustion sources were observed indoors at the basement workshop working area contributing to $\mathrm{CO} \mathrm{I} / \mathrm{O}$ ratio $>1$. Lower-floor units tend to have higher levels of $\mathrm{CO}$ since outdoor air can be a major source of indoor $\mathrm{CO}$ [16] which is particularly true in urban congested areas where traffic emissions contribute to higher $\mathrm{CO}$ levels.

Table 3: $\quad$ I/O ratios of air pollutants.

\begin{tabular}{lcccc}
\hline \multirow{2}{*}{ Working areas } & \multicolumn{4}{c}{$\mathrm{I} / \mathrm{O}$ ratio } \\
\cline { 2 - 5 } & $\mathrm{CO}$ & $\mathrm{CO}_{2}$ & $\mathrm{PM}_{2.5}$ & $\mathrm{TVOC}$ \\
\hline Clinic & 0.70 & $\mathbf{1 . 4 6}$ & $\mathbf{1 . 1 1}$ & $\mathrm{NR}^{\mathrm{a}}$ \\
Clinic waiting area & 0.97 & $\mathbf{1 . 4 8}$ & 0.32 & $\mathbf{1 . 6}$ \\
Lobby & 0.82 & $\mathbf{1 . 1 3}$ & $\mathbf{1 . 1 6}$ & $\mathrm{NR}$ \\
Reception & 0.79 & $\mathbf{1 . 6 0}$ & $\mathbf{1 . 0 4}$ & $\mathrm{NR}$ \\
Staff office & 0.65 & $\mathbf{1 . 1 9}$ & 0.21 & $\mathrm{NR}$ \\
Corridor & $\mathbf{1 . 3 6}$ & 0.93 & 0.20 & $\mathbf{3}$ \\
Pediatrics patient room & 0.70 & $\mathbf{1 . 1 9}$ & 0.19 & $\mathrm{NR}$ \\
Emergency room (ER) & $\mathbf{1 . 5 6}$ & $\mathbf{1 . 2 9}$ & 0.90 & $\mathrm{NR}$ \\
Basement workshop & $\mathbf{1 . 6 6}$ & $\mathbf{1 . 4 2}$ & 0.25 & $\mathrm{NR}$ \\
Meeting room & $\mathbf{1 . 6 9}$ & $\mathbf{1 . 0 9}$ & 0.86 & $\mathbf{3}$ \\
\hline
\end{tabular}

${ }^{a}$ No TVOC levels were recorded.

In all working areas the $\mathrm{CO}_{2}$ levels were $<1000 \mathrm{ppm}$, but indoor levels exceeded outdoors, resulting $\mathrm{CO}_{2} \mathrm{I} / \mathrm{O}$ ratios $>1$ suggesting human metabolism contributing to the higher indoor levels of $\mathrm{CO}_{2}$ as compared to outdoors. These levels can be improved by increased ventilation rates to prevent potential sick building syndrome (SBS) reported at exposure levels $>1000 \mathrm{ppm}[17,18]$.

While $\mathrm{PM}_{2.5} \mathrm{I} / \mathrm{O}$ ratios were mostly $<1$ indicating a relatively cleaner indoor environment than outdoors and minimal indoor $\mathrm{PM}_{2.5}$ sources, indoor levels exceeded outdoor concentrations during a dust storm and recorded $\mathrm{I} / \mathrm{O}$ ratios of $1.11,1.16$, and 1.04 at the clinic, lobby and reception working areas, respectively. High levels of $\mathrm{PM}_{2.5}$ are mostly accompanied with human activities and dust storms that can alter indoor $\mathrm{PM}_{2.5}$ levels [14]. A high correlation $(r=$ 0.69 ) was recorded between indoor and outdoor $\mathrm{PM}_{2.5}$ levels suggesting that indoor environments are directly affected by outdoor activities (Figure 2). Table 4 shows the Pearson correlation factor $(r)$ between indoor $\mathrm{PM}_{2.5}$ levels and outdoor levels of some working areas. Other areas (staff office, corridor, pediatrics patient room, ER, basement workshop and meeting room) with central air conditioning systems exhibited $\mathrm{PM}_{2.5} \mathrm{I} / \mathrm{O}$ ratios $<1$ consistent with previous studies $[19,20]$ that reported lower levels of particulate matter in buildings with central air conditioning systems equipped with filtration units.

Recorded TVOC I/O ratios were $>1$ at the clinic waiting area, corridor and meeting room probably due to the usage of frequent floor-cleaning chemicals and air refreshers that are sources of TVOC [12]. Although TVOC I/O ratios were $>1$, measured concentrations indoors and outdoors are below threshold levels. 


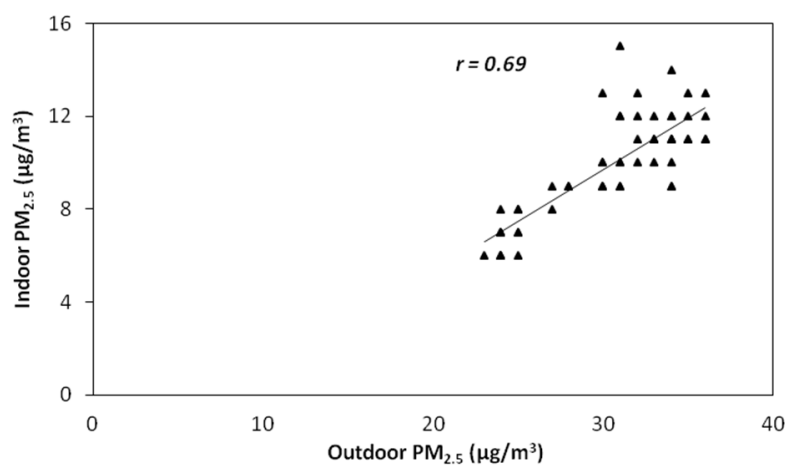

Figure 2: Indoor and outdoor $\mathrm{PM}_{2.5}$ correlation at clinic working area.

Table 4: Pearson linear correlation (r) of indoor-outdoor PM2.5 at selected working areas.

\begin{tabular}{lccccc}
\hline & \multicolumn{5}{c}{ Outdoor $^{a}$} \\
\cline { 2 - 6 } Indoor & $\begin{array}{c}1^{\text {st }} \text { floor } \\
\text { entrance }\end{array}$ & $\begin{array}{c}8^{\text {th }} \text { floor } \\
\text { mechanical }\end{array}$ & $\begin{array}{c}8^{\text {th }} \text { floor } \\
\text { mechanical }\end{array}$ & $\begin{array}{c}\text { ER main } \\
\text { entrance }\end{array}$ & $\begin{array}{c}8^{\text {th }} \text { floor } \\
\text { mechanical }\end{array}$ \\
\hline Reception & $\mathbf{0 . 4 6}$ & - & 0.39 & & \\
Staff office & - & - & $\mathbf{0 . 6 9}$ & & \\
Corridor & - & - & - & 0.38 & \\
ER & - & - & - & - & 0.23 \\
Basement workshop & - &
\end{tabular}

${ }^{a}$ Sampling took place at outdoor locations simultaneously with indoor working areas.

\subsection{Urban versus rural}

Higher $\mathrm{PM}_{2.5}$ and $\mathrm{CO}$ levels were recorded in urban hospitals $\left(\mathrm{PM}_{2.5}=81 \pm\right.$ $12 \mu \mathrm{g} / \mathrm{m}^{3}$ and $\mathrm{CO}=4.62 \pm 0.71 \mathrm{ppm}$ ) compared to a hospital in a rural area $\left(\mathrm{PM}_{2.5}=27 \pm 6.5 \mu \mathrm{g} / \mathrm{m}^{3}\right.$ and $\left.\mathrm{CO}=1.22 \pm 0.43 \mathrm{ppm}\right)$. The levels of outdoor $\mathrm{PM}_{2.5}$ in urban hospitals (A and $\mathrm{B}$ ) exceeded that of rural hospital $\mathrm{C}$ by 1.7 on regular sampling days and 2 folds during a dusty weather (Figure 3). The indoor levels of $\mathrm{PM}_{2.5}$ were also higher than the WHO standard in one hospital (B) during a dust storm. Although affected by outdoor levels, most indoor $\mathrm{PM}_{2.5}$ and $\mathrm{CO}$ concentrations in urban and rural hospitals were below standards (Figure 3).

The high $\mathrm{PM}_{2.5}$ and $\mathrm{CO}$ levels in urban setting suggest the contribution of dusty weather, construction activities and vehicular emission. $\mathrm{PM}_{2.5}$ and $\mathrm{CO}$ measurements at the rural hospital $(\mathrm{C})$ indicate a relatively cleaner outdoor and indoor environment reflecting the pristine nature of an area surrounded by greenery which acts as a sink for most air pollutants [21]. 


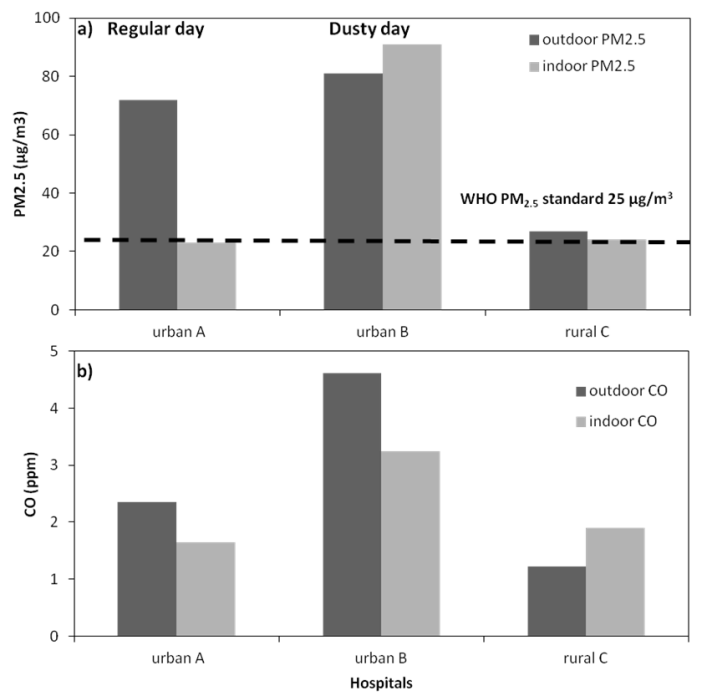

Figure 3: Outdoor and indoor levels at urban and rural hospitals (A, B and C): (a) $\mathrm{PM}_{2.5}\left(\mu \mathrm{g} / \mathrm{m}^{3}\right)$ and (b) $\mathrm{CO}(\mathrm{ppm})$.

\section{Conclusion}

Assessing exposure to air pollutants in facilities with high vulnerability (such as hospitals) is imperative for health protection. The results of this study show that:

- Higher levels of $\mathrm{CO}_{2}(690 \pm 65 \mathrm{ppm})$ and TVOC $(0.30 \pm 0.10 \mathrm{ppm})$ indoors $(p<0.05)$ compared to outdoors $(471 \pm 85 \mathrm{ppm}$ and $0.10 \pm 0.07 \mathrm{ppm})$.

- While $\mathrm{PM}_{2.5}$ indoor/outdoor (I/O) ratios was mostly $<1$ indicating a cleaner indoor environment and minimal indoor $\mathrm{PM}_{2.5}$ sources, indoor levels exceeded outdoor concentrations during a dust storm and reached a 2.6 fold higher than the WHO standard.

- A high correlation $(r=0.69)$ was recorded between indoor and outdoor $\mathrm{PM}_{2.5}$ levels suggesting that indoor environments are directly affected by outdoor levels.

- Higher $\mathrm{PM}_{2.5}$ and $\mathrm{CO}$ levels were recorded in urban hospitals $\left(\mathrm{PM}_{2.5}=\right.$ $81 \pm 12 \mu \mathrm{g} / \mathrm{m}^{3}$ and $\left.\mathrm{CO}=4.62 \pm 0.71 \mathrm{ppm}\right)$ compared to rural $\left(\mathrm{PM}_{2.5}=27 \pm\right.$ $6.5 \mu \mathrm{g} / \mathrm{m}^{3}$ and $\mathrm{CO}=1.22 \pm 0.43 \mathrm{ppm}$ ) suggesting the contribution of dusty weather, construction activities and vehicular emission to urban levels of $\mathrm{PM}_{2.5}$ and $\mathrm{CO}$ in hospitals.

Future work will explore how different ventilation types, management of human activities and potential sources of indoor pollutants can improve indoor air quality and develop measures for improved control and protection of patients, employees, and visitors alike and alleviate potential health impacts for a most vulnerable segment of a community. 


\section{Acknowledgements}

This study is supported through joint funding from the Lebanese National Council for Scientific Research and the American University of Beirut.

\section{References}

[1] Finlayson-Pitts, B.J. \& Pitts, J.N.J. Chemistry of the Upper and Lower Atmosphere. Academic Press: San Diego, pp. 20-50, 2000.

[2] Ian Colbeck. Environmental Chemistry of Aerosols. Blackwell Publishing Ltd: 9600 Garsington Road, Oxford, UK, 2008.

[3] Wuebbles, J.D., Lei, H., Lin, J., Intercontinental transport of aerosols and photochemical oxidants from Asia and its consequences. Environmental Pollution, 150, pp. 65-84, 2007.

[4] Usher, C.R., Michel, A.E., Grassian, V.H., Reactions on Mineral Dust. Chemical Reviews, 103, pp. 4883-4939, 2003.

[5] Vardoulakis S., Human Exposure: Indoor and Outdoor. Royal Society of Chemistry, 28, pp. 85-107, 2009.

[6] Singer, B.C., Hodgson, A.T., Hotchi, T., and Kim, J.J., Passive measurement of nitrogen oxides to assess traffic-related pollutant exposure for the East Bay Children's Respiratory Health Study. Atmospheric Environment. 38(3): pp. 393-403, 2004.

[7] Pongpiachan, S., and Paowa, T., Hospital out-and-in-patients as functions of trace gaseous species and other meteorological parameters in ChiangMai, Thailand. Aerosol and Air Quality Research. 15(2), pp. 479-493, 2015.

[8] Cengiz, M.A., and Terzi, Y., Comparing models of the effect of air pollutants on hospital admissions and symptoms for chronic obstructive pulmonary disease. Cent. Eur. J. Public Health. 20, pp. 282-286, 2012.

[9] Zhang, Z., Wang, J., Chen, L., Chen, X., Sun, G., Zhong, N., Kan, H., and $\mathrm{Lu}$, W., Impact of haze and air pollution-related hazards on hospital admissions in Guangzhou, China. Environ. Sci. Pollut. Res. Int. 21, pp. 4236-4244, 2014.

[10] Xie, Y.B., Chen, J., and Li, W., An assessment of $\mathrm{PM}_{2.5}$ related health risks and impaired values of Beijing residents in a consecutive high-level exposure during heavy haze days. Huan Jing Ke Xue. 35, pp. 1-8, 2014.

[11] Eames, I., Tang, J.W., Li, Y., and Wilson, P., Airborne transmission of disease in hospitals. J. R. Soc. Interface, 6, pp. 697-702, 2009.

[12] Erdogan M.S., Yurtseven E., Erginoz E., Suphi V., Koksal S., Yuceokur, A.A., Total volatile organic compuunds (TVOC), carbon monoxide (CO), carbon dioxide $\left(\mathrm{CO}_{2}\right)$ concentrations in the hospital building of a medical faculty in Istanbul, Turkey. Nobel Medicus, 18, pp. 66-72, 2009.

[13] Helmis C.G., Tzoutzas J., Flocas H.A., Halios CH., Stathopulou OI., Indoor air quality in a dentistry clinic. Sci Total Environ, 337, pp. 349$365,2007$. 
[14] Dement'eva, A. L., Zhamsueva, G.S., Zayakhnove, A.S., Tsydypov, V.V., Ayurzhanaev, A. A., Azzayaa, D., Oyunchimeg, D., Mass concentration of PM10 and PM2.5 fine-dispersed aerosol fractions in the Eastern Gobi Desert. Russian Meteorology and Hydrology, 38 (2), pp. 80-87, 2013.

[15] Chowdhury Z., Campanella L., Gray C., Al Masud A, Marter-Kenyon J., Pennise D., et al. Measurement and modeling of indoor air pollution in rural households with multiple stove interventions in Yunnan, China. Atmospheric Environment, 67, pp 161-169, 2013.

[16] Jo W.K., Lee J.Y., Indoor and outdoor levels of respirable particulates $\left(\mathrm{PM}_{10}\right)$ and carbon monoxide $(\mathrm{CO})$ in high-rise apartment buildings. Atmospheric Environment, 40, pp. 6067-6076, 2006.

[17] Erdmann C.A., Apte M.G., Mucous membrane and lower respiratory building related symptoms in relation to indoor carbon dioxide concentrations in the 100-building BASE dataset. Indoor Air, 14, pp. 127134, 2004.

[18] Norback D., Nordstrom K., Sick building syndrome in relation to air exchange rate, $\mathrm{CO}(2)$, room temperature and relative air humidity in university computer classrooms: an experimental study. Int Arch Occ Env Hea, 82, pp. 21-30, 2008.

[19] Zuraimi M.S., T K.W., Chew F.T., Ooi P.L., The effects of ventilation strategies of child care centers on indoor air quality and respiratory health of children in Singapore. Indoor Air, 17, pp. 317-327, 2007.

[20] Lin L.Y., Chen H.W., Su T.L., Hong G.B., Huang L.C., Chuang K.J., The effects of indoor particle exposure on blood pressure and heart rate among young adults: an air filtration-based intervention study. Atmospheric Environment, 45, pp. 5540-5544, 2011.

[21] Hurtt G.C., Pacala S.W., Moorcroft P.R., Caspersen J., et al., Projecting the future of the US carbon sink. Proceedings of the National Academy of Sciences, 99, pp. 1389-1394, 2002. 